\title{
Modelling Organisational Behavior with Process Reference Models
}

\author{
David Tuffley \\ School of ICT, Griffith University, Brisbane, Queensland, 4111, Australia
}

\begin{abstract}
Process Reference Models are traditionally used to specify the "hard" or easily identifiable ICT components such as Databases, Applications, Systems and Infrastructure. More difficult to describe are the "softer" or more intangible aspects of a modern organization, for example leadership, innovation and competencies / capabilities. This paper proposes a new approach for defining and categorizing the activities of Leadership within the modern Organization. The approach emerges from the Process Reference Model that can be generalized across domains. This approach has the potential to extend and streamline the development of the process, strategy and management layers within the modern organisation. This new category of process model is termed a Reference Model of Organisational Behavior (RMOB). These are fully conformant with the requirements for Process Reference Models, as prescribed by ISO/IEC 244774 and ISO/IEC 15504. The RMOB has all the strength and flexibility of these robust Software Engineering tools, coupled with the ability to describe in process terms what was previously considered too difficult to describe. Furthermore a reliable assessment model can be derived that allows for objective capability assessments to be performed.
\end{abstract}

Keywords Software Engineering Process Model, Process Reference Model, Reference Model of Organizational Behavior, Project Management, Leadership

\section{Introduction}

Historically, Software Engineering process models have concerned themselves with performing the right tasks in the right way and in the right sequence to get the job done. Activities are performed and artefacts created in a largely externalised set of activities that can be observed and assessed against an objective assessment model. But can a process model developed in accordance with ISO/IEC 15504 and ISO/IEC 24774 be said to be a PRM when it does not fit the orthodox conception of a PRM? This paper examines this question and proposes a new category of PRM, the Reference Model of Organisational Behavior supported by a Process Assessment Model. It also discusses the preliminary results of industry trials.

Process models developed in accordance with ISO/IEC 15504 and ISO/IEC 24774 can arguably be called a Process Reference Model (PRM), particularly when the draft model has had all of its outcomes validated by the existence of artefacts and/or activities identified during multiple review iterations involving practitioners and process model experts. In addition, the model may be used by an external observer to describe the behavior of an effective leader. Combine

* Corresponding author:

d.tuffley@griffith.edu.au (David Tuffley)

Published online at http://journal.sapub.org/se

Copyright (C) 2012 Scientific \& Academic Publishing. All Rights Reserved these factors and a strong argument exists for this position.

But the orthodox view in software engineering sees PRMs as high-level descriptions of ordered tasks needed to achieve desired project outcomes. The focus is on external entities that can be observed and assessed against an objecti ve assessment model.

A difficulty arises though when trying to reconcile the orthodox view of PRMs with a specific PRM focused on the elusive qualities of Leadership. Despite thousands of books and papers written on the topic of leadership over centuries, no commonly agreed definition yet exists[1]. Leadership qualities derive partly from a set of personality factors residing in the leader and partly from explicit actions performed by the leader at the team and organisational level. While the explicit actions can be directly observed, the implicit qualities cannot be observed, only their effects (as manifested by the attitudes and activities displayed by the leader).

A PRM for leadership of complex virtual teams describes aspects of desired organisational behavior that if performed repeatedly will become institutionalised and result in consistently achieving the prescribed purpose. This approac $h$ re-focuses attention from conformance to prescribed activities and tasks, to a focus on the demonstration of desired organisational behavior, taking us away from the traditional role of a PRM. This departure from the orthodox conception of a PRM may not pass unchallenged by interested observers, hence the proposed new category of 
PRM. Another reason is that leadership is just one of many desirable organisational behaviors that might be facilitated in organisations by a PRM.

How then to conceptualise this new role for a PRM? A logical answer is that the Leadership PRM is sufficiently different in application that is in a new category of process reference model, described provisionally as a Reference Model for Organisational Behavior (RMOB).

This new category of PRM and associated assessment model opens up the field across disciplines for others to develop models of organisational behavior covering a range of activities (for example IT governance), acquiring the means to assess and improve organisational behavior.

Reference Models for Organisational Behavior (RMOB) arguably represent a significant new application of Process Reference Models and Process Assessment Models in domains outside software, systems engineering and service management.

\section{Can Leadership Be Described As a Process}

Leadership is not alone in the broad category of behaviors engaged in by organisations as they pursue their objectives. If leadership can be described in a Process Reference Model (PRM) and supported by a PAM, then theoretically so too might these other behaviors not yet serviced by a PRM. For example, ISO/IEC 15504 offers organizations the means to develop and assess their integrated teaming capability against the measurement framework prescribed by ISO/IEC 15504[27].

We begin by examining whether there are grounds to believe that PRMs are applicable in addressing leadership in a software engineering environment? It will be seen from the discussion that PRMs and Model Based Process Improvement (MBPI) can arguably be applied to a range of software engineering challenges, including the challenge of project leadership.

As seen in Figure 1, there are two broad justifying reasons; first that Leadership can be taught and learned by those who would practice it[3][4][5]. The second reason is that the defining of processes is necessary for organisational effectiveness[6]. As Deming said, if you cannot describe what you are doing as a process, then you don't know what you are doing[7].

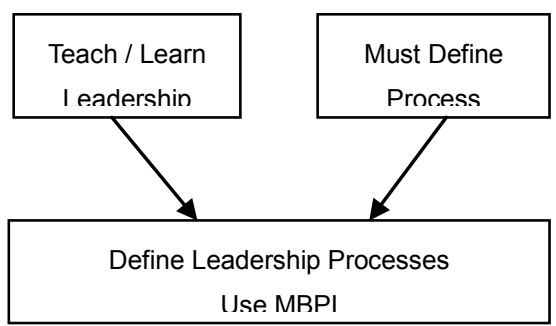

Figure 1. MBPI enables leadership processes to be defined
The conceptual overview diagram in Figure 2 illustrates the evolution of the question how can the challenge of more effective virtual team leadership be met? Assuming that the leadership factors could be identified from a broad literature review, then a Process Reference Model is a logical way for these factors to be formalised and applied in real situations.

The basic topic of team functioning was examined first, which led to the identification of what characteristics are likely to create a successful team. Arising from this work on successful teams, leadership is clearly identified as being of critical importance.

The conceptual overview acknowledges the basic distinction between co-located and virtual teams, and that integrated teams can be either. Virtual teams do not have to be integrated but commonly are. Integrated teams do not have to be distributed, but commonly are. Therefore, the characteristics of successful teams and successful leaders are considered for both co-located and virtual teams, culminating in the characteristics of successful leaders of integrated teams operating in virtual environments.

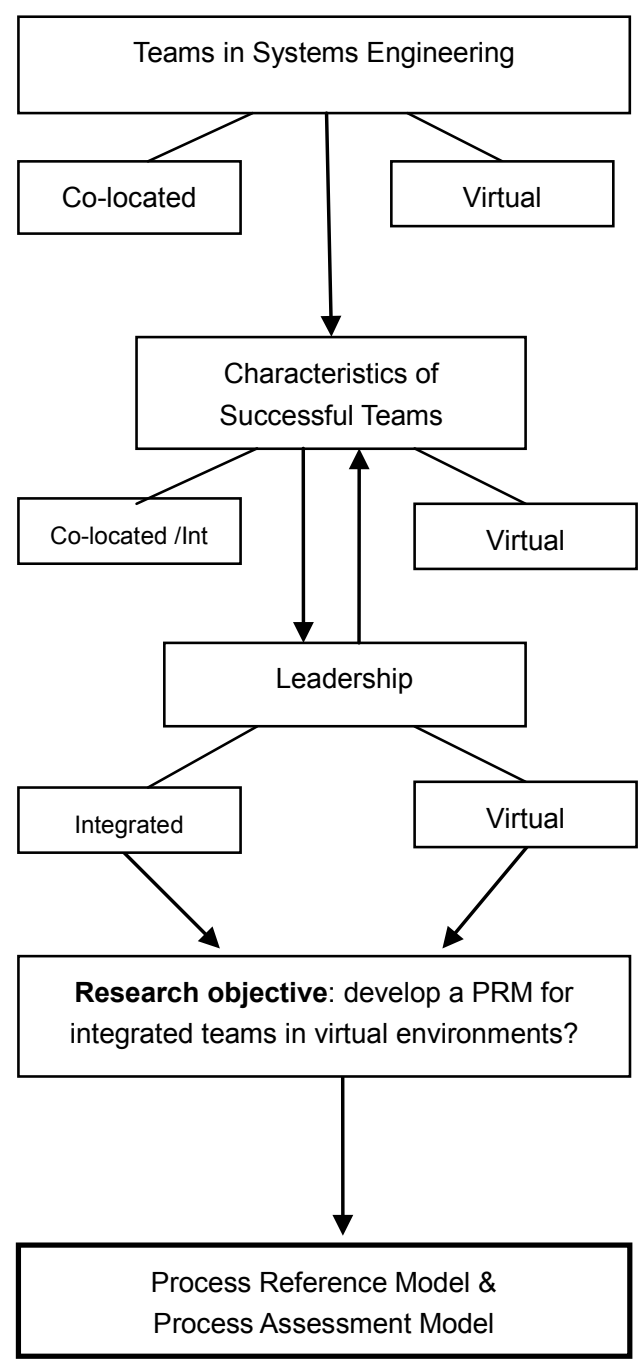

Figure 2. Conceptual overview of how Leadership PRM \& PAM evolved 


\section{Model Based Process Improvement As a Solution To Rising Organisational Complexity}

The business of managing complex projects across dispersed geographical locations has never been more difficult, given the rising complexity of the global economic environment and the multi-national corporate entities that now inhabit this world. There is a clear need to find improved ways of managing this often difficult process now and into the future[2].

Model Based Process Improvement (MBPI) potentially offers the means by which organisational challenges such as the leadership of complex virtual teams can be met. MBPI has not (to the knowledge of the author) been used to address leadership, though there is arguably a sound basis for thinking that it can be used in this way.

MBPI aims generally to improve the performance and maturity of an organisation's processes. It combines the discipline of process improvement with the several international standards and frameworks now in use (i.e. ISO/IEC 15504, CMMI). Combining this awareness of process performance with internationally recognised standards is advantageous to organisations. It affords a structured and comprehensive framework as a way forward and prescribes in general terms the scope of activities required to systematically improve their process maturity.

Heston and Phifer[8] ascribe the following organisational benefits to MBPI:

Improving consistency and repeatability: consistency and repeatability assist with minimising process variation, a major source of product defects. It also allows project staff to move into and out of projects more easily by having clearly defined roles and responsibilities.

Improving communication: achieved through the adoption of a common vocabulary with clearly prescribed meanings that allows project staff, clients and business partners to communicate with less ambiguity.

Enabling more improvement: process improvement programs create an environment which is conducive to further improvement. Beyond consistency and repeatability comes the ability to measure and record process performance. This performance data can then be used to plan further improvements and to benchmark against best practice.

Providing motivation: objective targets, for example being assessed at a certain level of maturity, become a visible motivator for project staff to maintain their efforts to improve process performance.

\section{Pre-cursors of MBPI}

As U.S. industry became increasingly concerned with maintaining competitive advantage in the post-WW2 period against resurgent Japanese and German manufacturing industries, the field of quality control emerged as an important strategic tool.
Seminal work by Deming[9], Crosby[10] and Juran [11],[12] laid the foundation for MBPI with the basic concept of continuous improvement. Deming was to some extent influenced by the Japanese Kaizen principle[13] of continuous improvement that had been applied to good effect in that country to improving the quality of manufactured goods.

The Deming Cycle (design the product, make it; test it thoroughly, release it to the market, test it in service and determine the user's view of it, and why the nonuser has not bought it, then feed the results back into an improved design) became a commonly practiced approach to product quality[9]. Like the Deming Cycle, the Juran Trilogy (quality planning, quality control, and quality improvement) defines an iterative feedback loop that results in continuous improvement. Crosby's management-centric approach[10] focuses on strategic planning for quality based on an iteratively improved understanding of product requirements. All three of these quality leaders seem to point in the same general direction by defining what quality means and using feedback to measure manage and achieve quality.

It is against this background that the field of MBPI for software development emerged from the early work of Humphrey[14], Paulk et al[15][16], Curtis et al[17], Basili[18], Kuvaja et al[19], ISO/IEC 15504:2003, and Wang et al[20][21].

The Process Reference Model (PRM) concept evolved in this milieu as a rational approach to the problem of how to represent effective processes for a variety of purposes. Such a representation must give detailed guidance on what an effective process looks like without limiting the practitioner's ability to adapt their existing processes to become more mature. Such a representation must also furnish structural coherence to the collection of process descriptions.

In keeping with the earlier work by Deming[9], Crosby[10] and Juran[11] in which quality objectives are defined, MBPI and the derived PRMs allows organisations to set objectives and priorities for process improvement. Process maturity can be cultivated, a shared language of process improvement adopted and when coupled with an Assessment Model, the means become available for organisations to benchmark the current state of their improvement methods.

Wang and King[22] define the discipline in the following way; 'model-based process improvement model is an operational model that describes process improvement methods based on model or standard-based assessment results.'

This definition accords with Clouse, Ahern \& Turner[23] who define MBPI as '...the use of a model to guide the improvement of an organisation's processes ... growing out of the quality management work of Deming, Crosby and Juran and ... aimed at increasing the capability of work processes.'

Clouse et al[23] go on to discuss that process improvement derives from significant long-term self 
-reflective focus on how the work is done, underscored by senior management support for process improvement efforts, and the use of capability maturity models (or PRMs generally) to provide a common set of process requirements that capture best practice and practical experience in ways that are useful.

The environment in which software engineering is performed in the modern world has become (a) steadily more complex, (b) performed by multi-disciplinary, distributed teams, and (c) is more influenced by process models[23]. The development of the CMMI is evidence of a more integrated approach to software engineering, based on MBPI in general and process models in particular. MBPI and process models are apparently well-suited to dealing with the rising complexity and demands of today's software engineering, and therefore possibly a fitting approach to dealing with problems such as how to optimise the leadership of integrated teams in virtual environments. To clarify the distinction between process models and process reference models, not all models in MBPI are PRMs. A PRM is a sub-set of process models, a specific type of process model that supports MBPI.

The literature on developing process reference models is limited. Rout and Simms[26] discuss the development of ISO/IEC 15504 against a background in the 1990's of increasing pressure to develop a unified and consensus -driven approach to software process assessment in order to mitigate the difficulties associated with frequent, costly and disruptive capability evaluations instigated by customers.

Seen in this context therefore, it is arguable that Model-Based Process Improvement has the capability to develop a PRM for Leadership of virtual teams, given the broad terms of reference of the discipline and its demonstrated achievements thus far.

\section{Reference Model of Organisational Behavior}

The RMOB was developed using Design Research[28] in which multiple review iterations are performed on the developed artefact[29][30].

Hevner[28] describes Design Research as a pragmatic research method, predicated on being relevant to real-world situations and making a clear contribution to the application environment. Hevner[28] describes Design Research as the embodiment of three inter-related cycles, these being the Relevance, Rigor and Design Cycles.

The application of Design Research principles to this project is in keeping with a traditional approach across engineering disciplines for the discovery of useful, real -world applicable solutions to problems that have not been amenable to an expedient solution.

Data collection was by a focus group review that was aimed at improving the usefulness and usability of the model. The review was performed by a rigorous examination of the model over a six hour period by a focus group comprised of four project managers, each of whom were actively coordinating the activities of a virtual team. Two of the project managers were from the IT projects segment of the higher education sector; the other two were from the systems development segment of the Australian Defense contractor sector. The group evaluated each process and associated outcomes for accuracy, understandability and comprehensiv eness. For most outcomes, individual work products were identified and recorded. All data was collected and incorporated into Version 1.1 of the model.

The data from the focus group was recorded into a pro-forma, as shown in the table below. The data included objective evidence that an outcome is actually being performed, and suggested improvements to the wording and content of the model.

Table 1. Focus group data collection pro-forma (sample)

1.1 Create and communicate a shared vision

Purpose: to perceive and communicate a guiding principle/idea

that captures the imagination of members to create a shared vision and inspire them with the enthusiasm to realise that vision. An aspect of charisma.

(Suggested change) Purpose: The purpose of the vision process is to create and communicate a shared vision in ways that inspires people to realize that vision

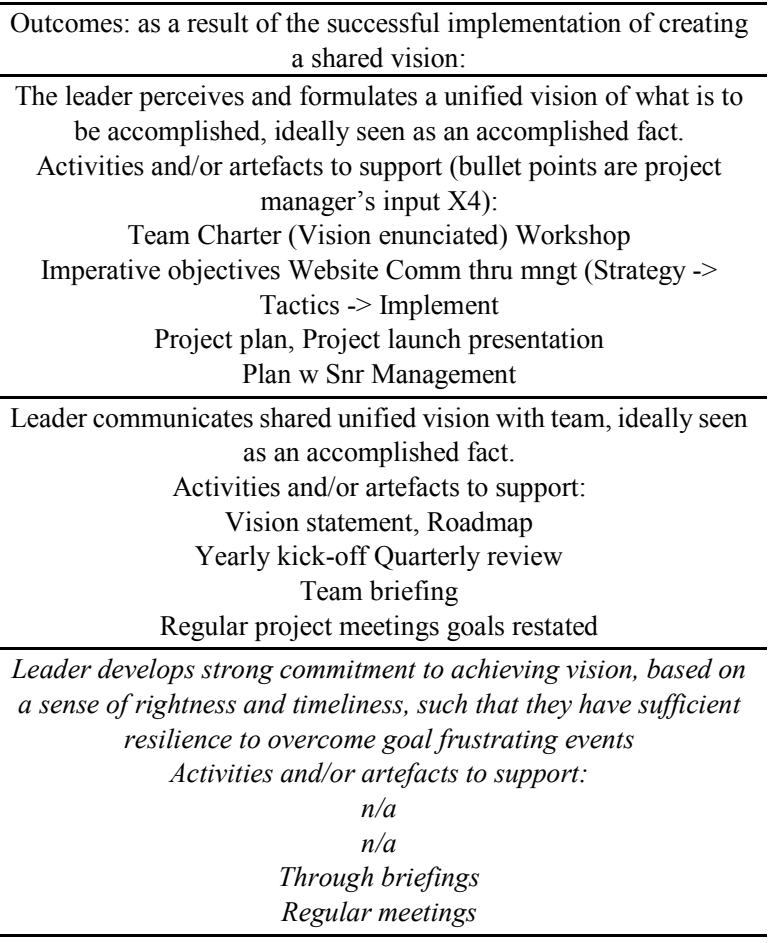

\section{Leadership PRM in Practice}

The Leadership PRM was developed using a Design Research approach in which an initial prototype was developed based on the broad literature and reviewed in a series of design iterations over an 18 month period (a total of six reviews). The reviews included the standard PRM -developer's method of practitioner and expert reviewers, plus an ISO/IEC 24774 conformance review to ensure the 
model met the requirements of that standard. The PRM was also validated with Dromey's Behavior Engineering[24], a formal method for checking content and syntax for errors and ambiguities that was developed initially for validating software requirements for complex systems, but which has proven a highly effective method for validating PRMs[25].

Having passed through these six reviews, the V1.0 PRM was released and reviewed again by a focus group over a full day. The group comprised two practitioner project managers and two experts on process models in software engineering. The terms of reference of this post-release review was to evaluate the efficacy of the leadership PRM, particularly in relation to (a) fitness for purpose, (b) organisation of and content of elements, and (c) what would make it more usable from a practitioner's point of view?

As a result of the review, V1.1 PRM was produced. This version incorporated the accumulated feedback from the focus group and resulted in substantial changes by (a) consolidating and merging several processes, (b) reordering the processes to reflect a sequence more naturally performed in projects, and (c) adding additional informative material relevant to virtual and/or integrated project environments. All of these changes were consistent with the review's terms of reference.

Table 2. Structure and content of PAM

\begin{tabular}{cc}
\hline & Leadership Process Assessment Model \\
\hline & Individual Process Group (IND) \\
\hline IND.1 & Vision \\
\hline IND.2 & Objective(s) \\
\hline IND.3 & Integrity \\
\hline IND.4 & Action-orientation \\
\hline IND.5 & Intelligence \\
\hline IND.6 & Individualized consideration \\
\hline IND.7 & Management-by-exception \\
\hline & Team Process Group (TEM) \\
\hline TEM.1 & Team requirements \\
\hline TEM.2 & Team recruitment \\
\hline TEM.3 & Team environment \\
\hline TEM.4 & Team formation \\
\hline TEM.5 & Team roles \\
\hline TEM.6 & Team rules \\
\hline TEM.7 & Team authority \\
\hline TEM.8 & Team performance management \\
\hline TEM.9 & Team development \\
\hline TEM.10 & Team \& home organization balance \\
\hline & Organisation Process Group (ORG) \\
\hline ORG.1 & Team boundaries \\
\hline ORG.2 &
\end{tabular}

Importantly for the purposes of this paper, the consensus opinion of the focus group was that the Leadership PRM is a usable model. They each wanted a copy of the update V1.1 PRM for use in their own projects. This feedback lends support to the argument that a Reference Model of Organisational Behavior that conforms to the requirements of a PRM in a software engineering sense can be a useful and usable artefact. Engineers tend to be rational and pragmatic when seeking solutions to problems.

Also emerging from this first post-release review was a Process Assessment Model (PAM) based on the Leadership PRM. This PAM was developed in accordance with ISO/IEC 15504:2004 Parts 1 and 2,

An example process from the PAM (Vision) is shown in Table 2 below. It and the other 15 processes have now been elaborated into a draft PAM. The first review established that a PAM which embodies at least the Process dimension is viable.

The second and subsequent reviews (V1.2 onwards) will investigate the feasibility of including the Capability dimension in the Leadership PAM. While it has been established during the validation of the PRM that each of the outcomes can be substantiated by the presence of artefacts and/or activities, it is not yet clear whether the discernable process indicators can be distinguished with sufficient clarity to establish the capability dimension. Only by performing a number of assessments using the draft PAM and accumulating data in the Work Products / Activities / Conditions section will we know whether a capability dimension is feasible. This work is on-going.

Table 3. Structure and content of PAM example 1

\begin{tabular}{|c|c|}
\hline Process ID & IND.1 \\
\hline $\begin{array}{l}\text { Process } \\
\text { Name: }\end{array}$ & Vision \\
\hline $\begin{array}{l}\text { Process } \\
\text { Purpose: }\end{array}$ & $\begin{array}{l}\text { The purpose of the vision process is to create and } \\
\text { communicate a shared vision in ways that inspires } \\
\text { people to realize that vision. }\end{array}$ \\
\hline $\begin{array}{c}\text { Process } \\
\text { Outcomes: }\end{array}$ & $\begin{array}{l}\text { As a result of successful implementation of the } \\
\text { vision process: } \\
\text { A vision of the goal(s) is created. } \\
\text { The vision of the goal(s) is communicated to the } \\
\text { team } \\
\text { Commitment by team to the shared vision is } \\
\text { gained }\end{array}$ \\
\hline \multirow[t]{3}{*}{ Practices: } & $\begin{array}{l}\text { IND.1.BP1: Create the vision. The leader } \\
\text { envisions a desirable future condition[Outcome } \\
1]\end{array}$ \\
\hline & $\begin{array}{c}\text { IND.1.BP2: Communicate the vision. The leader } \\
\text { communicates the vision in a way that creates } \\
\text { positive expectation in the team } \\
\text { members[Outcome } 2 \text { ]. }\end{array}$ \\
\hline & $\begin{array}{l}\text { IND.1.BP3: Commitment to vision by team. The } \\
\text { leader obtains commitment from the team } \\
\text { members for the realisation of the vision, making } \\
\text { it a shared vision[3]. }\end{array}$ \\
\hline \multicolumn{2}{|r|}{ Work Products / Activities / Conditions } \\
\hline Inputs & Outputs \\
\hline \multirow[t]{2}{*}{ Business goa } & Team Charter[Outcome 1] \\
\hline & $\begin{array}{c}\text { Imperative Objectives[Outcome } \\
1]\end{array}$ \\
\hline $\begin{array}{c}\text { Customer } \\
\text { requirements[Outcome 1] }\end{array}$ & Project Plan[Outcome 1] \\
\hline
\end{tabular}

Note that the PAM can be used in three possible ways, (a) by project managers to evaluate their own practice, and 
engage in self-improvement by benchmarking against best-practice, and

(b) by organisations wishing to improve their internal management capability, and

(c) theoretically by external agencies wishing to evaluate a potential supplier's management capability (though this would be some distance away since the capability dimension has not been established).

Table 4. Structure and content of PAM example 2

\begin{tabular}{cc}
\hline Process ID & IND.2 \\
\hline Process Name: & Objectives \\
\hline $\begin{array}{c}\text { Process } \\
\text { Purpose: }\end{array}$ & $\begin{array}{c}\text { The purpose of the objectives process is create and } \\
\text { communicate objective(s) based on the vision and } \\
\text { derived goals. }\end{array}$ \\
\hline $\begin{array}{c}\text { Process } \\
\text { Outcomes: }\end{array}$ & $\begin{array}{c}\text { As a result of successful implementation of the } \\
\text { objectives process: }\end{array}$ \\
& $\begin{array}{c}\text { Practical objective(s) for goal(s) achievement are } \\
\text { developed. }\end{array}$ \\
& $\begin{array}{c}\text { Positive expectation for achieving objective(s) is } \\
\text { encouraged. }\end{array}$ \\
Practices: & $\begin{array}{c}\text { IND.2.BP1: Develop objectives. The leader derives } \\
\text { a set of practically worded objectives from the } \\
\text { shared vision and subsequent goals that give the } \\
\text { team a concrete set of outcomes to } \\
\text { achieve.[Outcome 1] }\end{array}$ \\
& $\begin{array}{c}\text { IND.2.BP2: Encourage positive expectation. The } \\
\text { leader generates an optimistic mind-set and outlook } \\
\text { in the team towards the achievement of the } \\
\text { objectives[Outcome 2] }\end{array}$ \\
&
\end{tabular}

\begin{tabular}{cc}
\hline \multicolumn{2}{c}{ Work Products / } \\
\hline Inputs & Octivities / Conditions \\
\hline Vision statement[Outcome 1] & Goals[Outcome 1] \\
\hline & Objectives[Outcome 1] \\
\hline Project plan[Outcome 1] & Goals[Outcome 1] \\
\hline Project launch[Outcome 2] & Objectives[Outcome 1] \\
& Positive expectation re \\
& vision[Outcome 2] \\
\hline Team briefing[Outcome 2] & Commitment to vision[Outcome 2] \\
\hline Yearly kick-off[Outcome 2] & Positive expectation re \\
& vision[Outcome 2] \\
\hline Quarterly review[Outcome 2] & Commitment to vision[Outcome 2] \\
\hline
\end{tabular}

\section{Conclusions}

This paper examines the question of whether an ISO/IEC 15504 and ISO/IEC 24774 conformant process model focusing on the elusive quality of leadership can be said to be a PRM when it does not fit the orthodox conception of a PRM?

The paper argues the position that while such a model might conform to the requirements of the normative references, and has been properly validated and reviewed by peers and experts, that it would be wise to avoid confusion by nominating models that deal with organisational behavior as Reference Models for Organisational Behavior, a category of Process Reference Model in the strict software engineering sense.
This conclusion is supported by an argument in favour of being able to effectively describe organisational behavior like leadership as a process, in a process reference model that conforms to the normative standards applicable to software engineering.

A Leadership PRM developed by a rigorous Design Research process and tested in preliminary trials and found to be useful by practitioners and experts is arguably a viable model. Strengthening this position is the draft Process Assessment Model that considers initially the process performance dimension, but which will be elaborated in on-going trials for the inclusion of the capability dimension.

The results so far have been encouraging. Not only is a Leadership PRM \& PAM useful its own right, but it also points to the possibility of developing other Reference Models for Organisational Behavior and PAMs covering various organisational behaviors in a range of disciplines including but not limited to financial institutions and banks, automotive systems and software, aerospace systems and software, medical device systems and software, IT service management, test process improvement, small and very small enterprises. This would significantly extend the breadth of application of the standardised approach to process assessment.

\section{ACKNOWLEDGMENTS}

The author gratefully acknowledges the guidance of Terry Rout and Peter Bernus in the development of this research.

This work was financially supported by GriffithUniversit y, Australia.

\section{REFERENCES}

[1] Yukl, G., (1994). Leadership in Organisations. Englewood Cliffs, N.J. Prentice-Hall.

[2] Herbsleb, J. Moitra, D., (2001). Global Software Development, IEEE Software, Vol 18, Issue 2, (16-20).

[3] Drucker, P. (1996). Managing in a Time of Great Change, Butterworth Heinemann, London.

[4] Bennis, W. (1994). On Becoming a Leader, What Leaders Read 1, Perseus Publishing, p 2.

[5] Humphrey, W.S., (2002). Winning with Software. Addison Wesley Longman, Reading Massachusetts.

[6] Repenning, N.P., Sterman, J.D., (1997). Getting Quality the Old-Fashioned Way: Self-Confirming Attributions in the Dynamics of Process Improvement. Sloan School of Management, MIT., Cambridge, MA. (Available at: http://web.mit.edu/jsterman/www/SDG/Attrib.pdf)

[7] Deming, W.E., (2000). Out of the Crisis, MIT Press, Cambridge MA. 
[8] Heston, K.M, Phifer, W, (2009). The Multiple Quality Models Paradox: How Much 'Best Practice' is Just Enough? Software Process Improvement and Practice. Wiley InterScience.

[9] Deming, W.E., (2000). Out of the Crisis, MIT Press, Cambridge MA.

[10] Crosby, P. B., (1979). Quality is Free: The Art of Making Quality Certain. New York: McGraw-Hill Book Company.

[11] Juran, J.M., (1988). Juran on Planning for Quality. New York: The Free Press.

[12] Juran, J.M., Seder, L.A., Gryna, F.M. (1974). Quality control handbook, 3rd Edition, McGraw-Hill.

[13] Imai, M (1986). Kaizen: The Key to Japan's Competitive Success, Random House, New York.

[14] Humphrey, W.S. (1988). Characterising the Software Process: A Maturity Framework, IEEE Software, March, pp.73-79.

[15] Paulk, M.C., Curtis, B. and Chrissis, B. (1993), Capability Maturity Model, Version 1.1, IEEE Software, July, pp.18-27.

[16] Paulk, M.C., Weber, C.V. and Curtis, B. (1995). The Capability Maturity Model: Guidelines for Improving the Software Process, SEI Series in Software Engineering, Addison-Wesley.

[17] Curtis, B., Kellner, M.I., Over, J. (1992), Process Modelling, Communications of the ACM, Vol.35, No.9, pp.75-90.

[18] Basili, V. (1993). The Experience Factory and Its Relationship to Other Improvement Paradigms, Proceeding s of 4th European Software Engineering Conference, LNCS 717, Springer-Verlag, pp. 68-83.

[19] Kuvaja, P., Simila, J., Kizanik, L., Bicego, A., Koch, G. and Saukkonen, S. (1994). Software Process Assessment and Improvement: The BOOTSTRAP Approach, Blackwell Business Publishers.

[20] Wang, Y., Court, I., Ross, M., Staples, G. and King, G. (1996). Towards a Software Process Reference Model, Proceedings of International Conference on Software Process Improvement (SPI96), Brighton UK, pp.145-166.

[21] Wang, Y. and King, G. (1999). Software Engineering Processes: Principles and Applications, CRC Press, USA.

[22] Wang, Y., King, G.A. (2000). Software Engineering Processes: Principles and Applications. CRC Press p. 61.

[23] Clouse, A., Ahern, D.M., \& Turner, R. (2003). CMMI ${ }^{\circledR}$ Distilled: A Practical Introduction to Integrated Process Improvement, Pearson, Boston, p4-5

[24] Dromey, R.G. (2006). Climbing Over the 'No Silver Bullet' Brick Wall, IEEE Software, Vol. 23, No. 2, pp.118-120.

[25] Tuffley, D., Rout, T (2009), Applying Behavior Engineering To Process Modelling, in Proceedings of the 1st Improving Systems and Software Engineering Conference (ISSEC), National Convention Centre, Canberra, Australia, 10-12 August 2009.

[26] Rout T.P., Simms P.G. (1997). Introduction to the SPICE Documents and Architecture. in SPICE: The Theory and Practice of Software Process Improvement and Capability Determination. El Emam K., Drouin, J-N, and Melo, W. eds. Brussels: IEEE Press.

[27] Tuffley, D.J. (2006). Implementing Integrated Teaming According to ISO15504, in Proceedings of the 6th International SPICE Conference on Process Assessment \& Improvement, Centre de Recherche Public Henri Tudor, Luxembourg.

[28] Hevner, A. (2007). A Three Cycle View of Design Science Research. Scandinavian Journal of Information Systems, 10(2) pp87-92.

[29] Vaishnavi, V.K., Kuechler, W. (2007) Design Science Research Methods and Patterns: Innovating Information and Communication Technology. CRC Press.

[30] Takeda, H., Veerkamp, P., Tomiyama, T., Yoshikawam, H. (1990). Modeling Design Processes. AI Magazine Winter: pp $37-48$. 